Article

\title{
Identification of a Male-Specific Amplified Fragment Length Polymorphism (AFLP) and a Sequence Characterized Amplified Region (SCAR) Marker in Eucommia ulmoides Oliv.
}

\section{Da-Wei Wang, Yu Li and Zhou-Qi Li*}

College of Forestry, Shaanxi Key Laboratory of Molecular Biology for Agriculture, Northwest A\&F University, Yangling, Shaanxi 712100, China; E-Mails: daweiwon@ 163.com (D.-W.W.); liyu0214@yahoo.cn (Y.L.)

* Author to whom correspondence should be addressed; E-Mail: lzhouqi @ yahoo.com.cn; Tel.: +86-29-870-829-92; Fax: +86-29-870-829-92.

Received: 1 January 2011; in revised form: 10 January 2011 / Accepted: 11 January 2011 / Published: 24 January 2011

\begin{abstract}
Eucommia ulmoides Oliv. is a dioecious species. Currently, there is no method to identify the sex during the juvenile stage that lasts a relatively long time. This study aimed to develop a sex specific Amplified Fragment Length Polymorphism (AFLP) marker for Eucommia ulmoides Oliv. Of a total of 64 AFLP primer combinations screened, primer combination E-ACA/M-CTT produced a 350 bp male-specific marker. This $350 \mathrm{bp}$ AFLP marker was converted into a 247 bp Sequence Characterized Amplified Region (SCAR) marker. Results suggest that the SCAR marker can be utilized for early sexual identification in Eucommia ulmoides Oliv., and it will greatly facilitate future breeding programs.
\end{abstract}

Keywords: AFLP; SCAR; male-specific; Eucommia ulmoides Oliv.

\section{Introduction}

Eucommia ulmoides Oliv., also called Du-zhong, a dioecious perennial angiosperm, is one of the oldest tonics in Chinese traditional medicine. The dry stem bark of Eucommia ulmoides Oliv. was officially listed in the Chinese Pharmacopoeia as an anti-hypertension and bone fracture treatment curative. Recent studies have shown that its bark has many pharmacological actions such as antifungal, 
inhibiting adipogenic differentiation and antihypertensive, anti-oxidation, anti-inflammatory, and low-density lipoprotein oxidative modification [1-5]. Du-zhong leaves contain many phyto-chemicals, such as polyphenolics, flavonoids and triterpenoids [6]. Du-zhong tea, the aqueous extract of Eulmoides leaves, has been already known as a functional food and commonly used for reduction of hypertension [7,8]. Gutta-percha is an industrial gum obtained from the seeds, barks and leaves of Eucommia ulmoides Oliv [9,10].

In Eucommia ulmoides, male and female trees have different practical uses. Usually the male plants are used for landscaping or as the street trees [11], whereas the leaves of female trees produce high quality vegetable oil that can be made into various health products [12]. The gum content in the female tree is significantly higher than that in the leaf of the male tree, and much higher in the seeds of both than in the bark and leaves [13,14]. In general, female trees are more valuable than the males. Therefore, sex identification in the early stages of growth is of great importance in plant management and utilization.

In practice, the cultivation of the unwanted males leads to wasted resources, which could be avoided if the sex of the plant could be identified at a juvenile stage. The commonly conducted morphological and cytological studies so far have failed to differentiate accurately the sex forms. It takes seven to eight years for the young seedlings to flower in nature, and it is difficult to distinguish the gender by morphological or cytological methods before they flower. Thus, it is necessary to develop a rapid and reliable technique for early sex identification of Eucommia ulmoides Oliv.

The AFLP (Amplified Fragment Length Polymorphism) technique was introduced by Vos et al. [15]. The major advantages of AFLP are (1) a high multiplex ratio, (2) a limited set of generic primers, and (3) the non-requirement for sequence information. To date, AFLP has been used in combination with BSA (Bulked Segregate Analysis) to identify sex linked markers in several dioecious plants [16], such as Asparagus officinalis L., Dioscorea tokoro, Ginkgo biloba, Pistacia, Ficus fulva, Rumex nivalis, Cannabis sativa L., ilex and Rumex acetosa [17-26].

Although the AFLP technique can be used to identify a large number of markers rapidly, the AFLP analysis procedure is complicated and costly. All these restrict the application for large-scale screening in breeding programs. Thus, it is necessary to convert AFLP markers into convenient and inexpensive Polymerase Chain Reaction (PCR)-based markers such as SCAR (Sequence Characterized Amplified Region) markers for MAS (marker-associated selection).

We report here the results of a search for sex markers using the AFLP technique to find differential DNA expression between mature male and female Eucommia ulmoides Oliv. The objective was to identify AFLP markers for sex and convert them to SCAR markers for early confirmation of the sex of plants and for the identification of genes related to sex distinction.

\section{Experimental Section}

\subsection{Plant Material and Genomic DNA Isolation}

Young leaves of 30 male and 30 female individual confirmed Eucommia ulmoides Oliv. trees were collected at Northwest A and F University, Yangling, Shaanxi province, and in Lingbao city, Henan province. The leaves from the 60 trees were divided into two groups. Ten males and 10 females were 
used in the first group for constructing the gene pool; the second group, including the other 40 male and female individuals, was used to verify the markers linked to sex.

Genomic DNA was isolated from the leaves from each individual tree according to the CTAB method with minor modifications [27]. The extracted DNA was diluted to a final concentration of $200 \mathrm{ng} / \mu \mathrm{L}$. To screen AFLP markers linked to sex, equivalent amounts of DNA from the leaves of 10 male individuals were pooled to construct male bulk NO.1 (BM) and 10 female were pooled to make NO.2 (BF). All genomic DNA was kept frozen at $-20{ }^{\circ} \mathrm{C}$ for digestion reaction with the AFLP technique.

\subsection{AFLP Assay}

Genomic DNA (500 ng) from the two bulks and 60 individuals was digested for $6 \mathrm{~h}$ at $37{ }^{\circ} \mathrm{C}$ with $10 \mathrm{U}$ EcoRI (New England BioLabs), $10 \mathrm{U}$ MseI (New England BioLabs), $2.5 \mu \mathrm{L}$ NEBuffer 4, $0.25 \mu \mathrm{L} 100 \times \mathrm{BSA}$, in a $25 \mu \mathrm{L}$ reaction volume adjusted with distilled water. In the same tube, $10 \mu \mathrm{L}$ ligation mixture was added consisting of $1 \mu \mathrm{L}$ EcoRI adapter $(5 \mathrm{pmol} / \mu \mathrm{L}), 1 \mu \mathrm{L}$ MseI adapter (50 pmol/ $\mu \mathrm{L}$ ), $3.5 \mu \mathrm{L} \mathrm{T}_{4}$ DNA ligase buffer, $400 \mathrm{U} \mathrm{T}_{4}$ DNA ligase (New England BioLabs) and $3.5 \mu \mathrm{L}$ distilled water. The reaction was incubated for $3 \mathrm{~h}$ at $16{ }^{\circ} \mathrm{C}$ and stopped by heating at $65^{\circ} \mathrm{C}$ for $10 \mathrm{~min}$. The ligated DNA was stored at $-20{ }^{\circ} \mathrm{C}$ until pre-amplification.

For pre-amplification, a mix was prepared composed of: $1 \mu \mathrm{L}$ of ligated DNA, $2.5 \mu \mathrm{L} 10 \times$ Taq DNA polymerase buffer, $0.5 \mu \mathrm{L}$ of $2 \mathrm{mM}$ dNTPs (Sangon), $0.6 \mu \mathrm{L}$ EcoRI pre-amplification primer (50 ng/ $\mu \mathrm{L}), 0.6 \mu \mathrm{L}$ MseI pre-amplification primer $(50 \mathrm{ng} / \mu \mathrm{L}), 1.5 \mu \mathrm{L} 25 \mathrm{mM} \mathrm{MgCl} 2,2.5 \mathrm{U}$ Taq DNA polymerase (Fermentas) and distilled water to a volume of $25 \mu \mathrm{L}$. The following cycling parameters were used for pre-amplification: 30 cycles of $30 \mathrm{~s}$ at $94{ }^{\circ} \mathrm{C}, 60 \mathrm{~s}$ at $56{ }^{\circ} \mathrm{C}$, and $60 \mathrm{~s}$ at $72{ }^{\circ} \mathrm{C}$, followed by $5 \mathrm{~min}$ at $72{ }^{\circ} \mathrm{C}$ for final extension. The PCR products were stored at $-20{ }^{\circ} \mathrm{C}$ until selective amplification.

The components for each $25 \mu \mathrm{L}$ amplification reaction were: $1 \mu \mathrm{L}$ diluted (1:30) pre-amplified products, $2.5 \mu \mathrm{L} 10 \times$ Taq DNA polymerase buffer, $0.5 \mu \mathrm{L}$ of $2 \mathrm{mM}$ dNTPs (Sangon), $1 \mu \mathrm{L}$ of EcoRI +3 primer $(50 \mathrm{ng} / \mu \mathrm{L}), 1 \mu \mathrm{L} \mathrm{MseI}+3$ primer $(50 \mathrm{ng} / \mu \mathrm{L}), 1.5 \mu \mathrm{L} 25 \mathrm{mM} \mathrm{MgCl} 2,2.5 \mathrm{U}$ Taq DNA polymerase (Fermentas) and distilled water. The AFLP products were amplified using touchdown PCR. An initial denaturation consisted of 1 cycle of $30 \mathrm{~s}$ at $94{ }^{\circ} \mathrm{C}, 30 \mathrm{~s}$ at $65{ }^{\circ} \mathrm{C}$, and $60 \mathrm{~s}$ at $72{ }^{\circ} \mathrm{C}$. The annealing temperature was then lowered by $0.7{ }^{\circ} \mathrm{C}$ per cycle during the first 13 cycles, and then 23 cycles were performed at $94{ }^{\circ} \mathrm{C}$ for $30 \mathrm{~s}, 56{ }^{\circ} \mathrm{C}$ for $30 \mathrm{~s}$, and $72{ }^{\circ} \mathrm{C}$ for $60 \mathrm{~s}$. Finally, selective amplification products were separated in $6 \%$ denaturing polyacrylamide gel and visualized by silver nitrate staining.

\subsection{AFLP Band Isolation and Sequencing}

The sex-specific fragments were excised from PAGE and extracted using the Long Range Gel Extraction Kit (CWBio). $1 \mu \mathrm{L}$ of extraction product was used as template or selective amplification with the same primer combination in the $25 \mu \mathrm{L}$ PCR reaction mix (as used for first round AFLP amplification, above). The PCR reaction products were separated by electrophoresis in $1.5 \%$ agarose gels (Invitrogen). DNA bands were excised from the gel and purified with UNIQ-10 EZ Spin Column 
DNA Gel Extraction Kit (Sangon), and the DNA was cloned into the plasmid vector pGEM-T (Promega). Colonies containing target fragments were sequenced by BeiJing BGI Co. Ltd.

\subsection{Conversion of AFLP Marker into SCAR Marker}

Primers were designed from the sequences of AFLP markers or extended AFLP markers using the software Primer 3. These primers were used to amplify genomic DNA of 30 male and 30 female individuals.

The SCAR reaction was carried out in a $25 \mu \mathrm{L}$ mixture, containing $1 \mu \mathrm{L}$ template DNA, $2.5 \mathrm{U}$ Taq DNA polymerase, $1.5 \mu \mathrm{L} 25 \mathrm{mM} \mathrm{MgCl} 2,0.5 \mu \mathrm{L}$ of $2 \mathrm{mM}$ dNTPs and 5 pmol each of forward and reverse primers as well as $2.5 \mu \mathrm{L} 10 \times$ PCR reaction buffer. The annealing temperature of the SCAR primers was optimized first, using the following cycling parameters: one cycle of $2 \mathrm{~min}$ at $94{ }^{\circ} \mathrm{C}$; 30 cycles of $30 \mathrm{~s}$ at $94{ }^{\circ} \mathrm{C}, 30 \mathrm{~s}$ at an annealing temperature, and $80 \mathrm{~s}$ at $72{ }^{\circ} \mathrm{C}$. Then $5 \mu \mathrm{L}$ PCR products from each sample were examined in a $1.5 \%$ agarose gel to confirm whether the SCAR primers were converted successfully.

\section{Results and Discussion}

In the AFLP assay combined with BSA, 64 AFLP primer combinations were used to identify putative markers in two DNA bulks of male and female individuals. Of these, nine primer combinations revealed polymorphism between two DNAs bulks. To confirm that the markers were linked to sex, 20 male and 20 female individuals were tested independently. The result shows that only primer combination E-ACA/M-CTT produced a 350 bp male-specific marker from all male samples that was absent from all female individuals (Figure 1).

Figure 1. Banding pattern of the male-specific AFLP marker (arrowhead) detected with the primer combination E-ACA/M-CTT. A 350 bp band is present in the males (M) but not the females $(\mathrm{F})$.

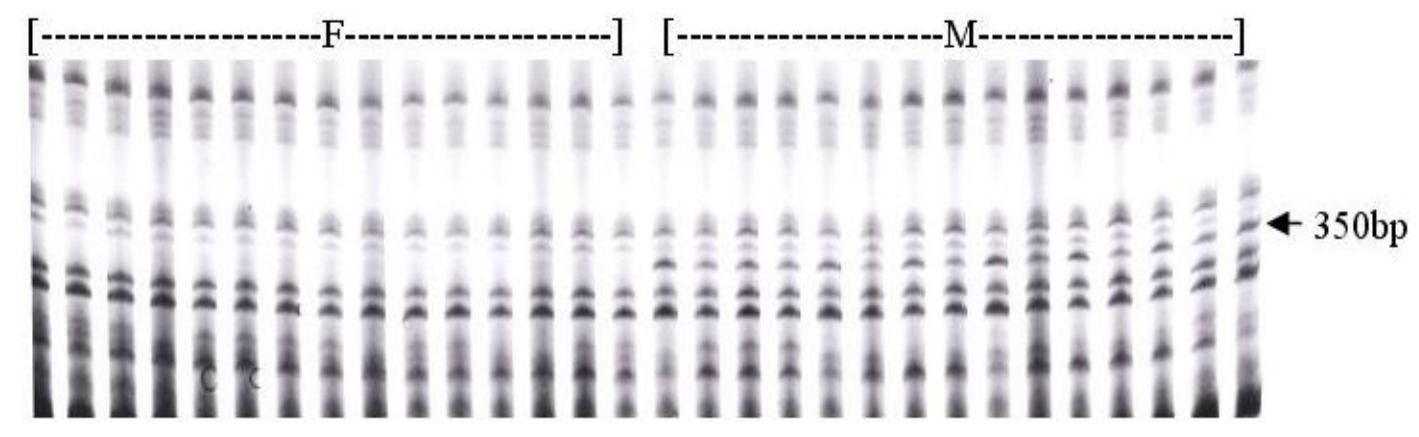

The sequence of the cloned male-specific fragment was determined. Based on the sequence, primers SDW1 and SDW2 were designed (Figure 2). The optimized annealing temperature of the SCAR primers was $65{ }^{\circ} \mathrm{C}$. At this annealing temperature, a $247 \mathrm{bp}$ SCAR marker was obtained. The agarose gel in Figure 3 shows that the marker was observed in all the male plants (M) but none of the female plants (F). The sequence of the 247 bp SCAR marker was determined, and it is completely coincided with the corresponding sequence of the AFLP maker. It is clear that the male-specific AFLP marker was successfully converted into a SCAR marker. 
Figure 2. The sequence of the male-specific marker. SDW1 and SDW2 were designed forward and reverse primers (underlined) for the SCAR marker. The bold section designates the sequence of the SCAR marker.

\section{TGACTGCGTA CCAATTCACA ACTCCACGCT GGAGCATACG CCGACTACAG ATCCTTCATG TAATCTCATT TGCACCCAGA GATGAGCTAG AATCTATGCA AGGACGTGTC GCTCTGAGCT SDW1 \\ CTGOGTTGTG COCTCGGCAA TCAGTTCAG GGACTTAGCX GCTCATCTCG ACTGGCTCOC

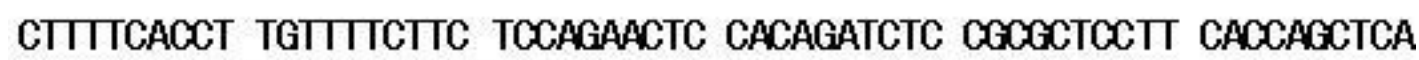 CTGOCGCAGG OCTGATAAAA GTTCGCGGGC TTCGCCAAAT GGGCOCAAAA GCOCAAGCOC}

GOTCGGG

GATGATTATC TCCTAAACGA CCCAGATTAT AAGTTACTCA GGACTCATCA CTACTAATAG AG

SDW2

Figure 3. The SCAR marker linked to sex in Eucommia ulmoides Oliv. analysis with the primer combination SDW1 and SWD2 of individual plants obtained from the male plant (arrow). A $247 \mathrm{bp}$ band is present in the males (M) but not in the females (F).

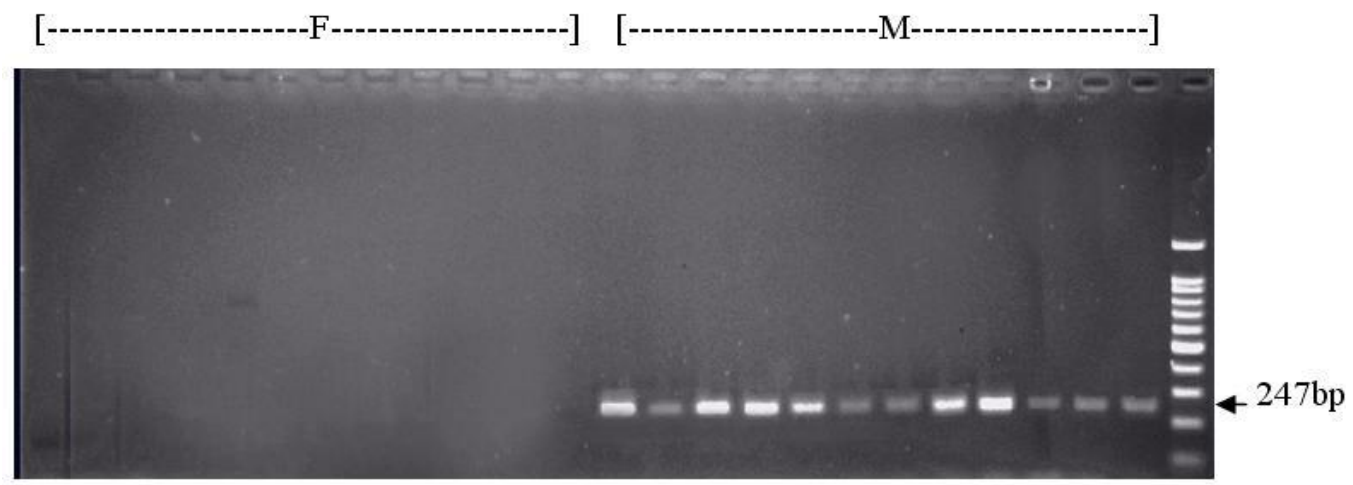

A search for the sequence in the databases of GENBANK showed that there is no homologous sequence in other species. This result may be expected since AFLP detect random genomic variation, most of which will be non-coding DNA [21].

We have shown that the combined strategy using bulked segregant analysis and AFLP is an efficient method for identifying sex specific markers in Eucommia ulmoides Oliv. In this paper, a total 64 pairs of AFLP primer combinations were screened, but only one male-specific marker was indentified. To our knowledge, this is the first report of a sex-specific AFLP marker in Eucommia ulmoides Oliv.

AFLP and RAPD (Random amplification polymorphic DNA) are frequently used molecular marker techniques to search for sex markers in dioecious plants [28]. These two molecular marker techniques have different advantages and shortcomings. Although the most simple and convenient technique used in practice, RAPD has low repeatability and stability [29-32]. AFLP can produce large number of candidate markers in a single experiment and it is highly reproducible [33]. However, AFLP markers are relatively costly and the method is technologically demanding, and this limits its application in breeding programs [34]. Thus, we converted an AFLP marker into a convenient and inexpensive 
PCR-based marker SCAR. A SCAR marker is a genomic DNA fragment at a single genetically defined locus that is identified by PCR amplification using a pair of specific primers. We derived the SCAR marker by cloning and sequencing the two ends of the amplified products of AFLP markers. The sequence was used to design pairs of primers that resulted in the reproducible amplification of single loci when high annealing temperatures were used. SCAR markers are advantageous over AFLP markers as they detect only a single locus, their amplification is less sensitive to reaction conditions, and they can be put in practice expediently [35].

There are a number of potential uses for sex specific markers, both in applied and basic research. In applied research for Eucommia ulmoides Oliv., plants require seven to eight years to reach reproductive maturity before the physical identification of sex of plants is possible, sex identification by molecular marker allows for early confirmation of sex without waiting for sexual maturity. Moreover, since there are distinct different practical uses between the two sexes of Eucommia ulmoides Oliv., early sex identification could be economically important for the breeding of this species. In basic research, isolation and characterization of the sex markers from mature Eucommia ulmoides Oliv. could provide valuable data for understanding the mechanisms of sex determination.

\section{Conclusions}

Here we present a male-specific AFLP and SCAR marker, which was stable in samples from two locations (Henan and Shaanxi province). This indicates that the male-specific marker linked to sex in Eucommia ulmoides Oliv. was not affected by environmental conditions. Thus, the male-specific marker could be recommended as a reliable genetic sex linked marker and hence used to detect the sexuality of Eucommia ulmoides Oliv. This result offers a rapid and simple method to determine the sex of Eucommia ulmoides Oliv. seedlings at an early stage, thereby saving time and economic resources when cultivating this species.

\section{Acknowledgements}

We would like to thank Keith E. Woeste (Purdue University, USA) for revising this manuscript. This study was supported by the National Natural Science Foundation of China (30771751).

\section{References}

1. Xiang, Y.; Huang, R.H.; Liu, X.Z.; Zhang, Y.; Wang, D.C. Crystal structure of a novel antigungal protein distinct with five disulfide bridges from Eucommia ulmoides Oliver. At an atomic resolution. J. Struct. Biol. 2004, 148, 86-97.

2. Lee, G.W.; Yoon, H.C.; Byun, S.Y. Inhibitory effect of Eucommia ulmoides Oliver on adipogenic differentiation through proteome analysis. Enzym. Microb. Tech. 2004, 35, 632-638.

3. Kwan, C.Y.; Chen, C.X.; Deyama, T.; Nishibe, S. Endothelium-dependent vasorelaxant effects of the aqueous extracts of the Eucommia ulmoides Oliv. Leaf and bark: Implications on their antihypertensive action. Vasc. Pharmacol. 2003, 40, 229-235.

4. Hsieh, C.L.; Yen, G.C. Antioxidant actions of Du-Zhong (Eucommia ulmoide Oliv.) toward oxidative damage in biomolecules. Life Sci. 2000, 66, 1387-1400. 
5. Yen, G.C.; Hsieh, C.L. Inhibitory effects of Du-zhong (Eucommia ulmoides Oliv.) against low-density lipoprotein oxidative modification. Food Chem. 2002, 77, 449-456.

6. Kawasaki, T.; Uezono, K.; Nakazawa, Y. Antihypertensive mechanism of food for specified health use: "Eucommia leaf glycoside" and its clinical application. J. Health Sci. 2000, 22, 29-36.

7. Nakazawa, Y. Functional and healthy properties of Du-zhong tea and their utilization. Food Ind. 1997, 40, 6-15.

8. Nakamura, T.; Odagiri, N.; Imai, R.; Yoshii, T.; Tagashira, E.; Nakata, C.; Asaumi, S.; Onizuka, S.; Yahara, M.; Nohara, N. Effect of Eucommia leaf (Eucommia ulmoides oliver Leaf; Du-zhong tea) extract on blood pressure(s). Nat. Med. 1997, 51, 392-398.

9. Tangparkdee, J. Structure and biosynthesis of trans-polyisoprene from Eucommia ulmoides. Phytochemistry 1997, 45, 75-80.

10. Yan, R.F. Eucommia ulmoides gum. In Polymeric Materials Encyclopedia; Salamone, J.C., Ed.; CRC Press: Boca Raton, FL, USA, 1996.

11. Zhang, K.J. Study of Eucommia in China; Shaanxi Science and Technology Press: Xi'an, China, 1992.

12. Zhou, Z.X. Eucommia ulmoides of China; Guizhou Science and Technology Press: Guiyang, China, 1993.

13. Wang, B.W.; Wang, Y.Q.; Mo, H.; Luo, L.X.; Li, M.X.; Cui, K.M. Comparison of cytology, apical buds and gutta content between staminate and pistillate of Eucommia ulmoides trees. Acta Bot. Sin. 1999, 41, 11-15.

14. Du, H.Y.; Du, L.Y.; Fu, J.M.; Du, X.S.; Zhang, X.Z. The difference and its pertinence analysis of the Gutta-percha content in organs of Eucommia ulmoides Oliv. J. Cent. South For. Univ. 2006, $26,1-4$.

15. Vos, P.; Hoger, R.; Blecker, M. AFLP: A new technique for DNA fingerprinting. Nucl. Acids Res. 1995, 23, 4407-4414.

16. Michelmore, R.W.; Paran, I.; Kesseli, R.V. Identification of markers linked to disease-resistance genes by bulked segregant analysis: A rapid method to detect markers in specific genomic regions by using segregating populations. Proc. Natl. Acad. Sci. USA 1991, 88, 9828-9832.

17. Spada, A.; Caporali, E.; Marziani, G.; Portaluppi, P.; Restivo, F.M.; Tassi, F.; Falavigna, A. A genetic map of Asparagus officinalis based on integrated RFLP, RAPD and AFLP molecular markers. Theor. Appl. Genet. 1998, 97, 1083-1089.

18. Reamon-Büttner, S.M.; Jung, C. AFLP-derived STS markers for the identification of sex in Asparagus officinalis L. Theor. Appl. Genet. 2000, 100, 432-438.

19. Terauchi, R.; Kahl, G. Mapping of the Dioscorea tokoro genome: AFLP markers linked to sex. Genome 1999, 42, 752-762.

20. Wang, X.M.; Song, W.Q.; Liu, S.; Li, X.L.; Chen, R.Y. AFLP markers related to sex in a dioecious plant Ginkgo biloba. Acta Sci. Nat. Univ. Nankaiensis (sativa) 2001, 34, 5-9.

21. Parrish, T.L.; Koelewijn, H.P.; van Dijk, P.J. Identification of a male-specific AFLP marker in a functionally dioecious fig, Ficus fulva Reinw. ex Bl. (Moraceae). Sex. Plant. Reprod. 2004, 17, $17-22$. 
22. Stehlik, I.; Blattner, F.R. Sex-specific SCAR markers in the dioecious plant Rumex nivalis (Polygonaceae) and implications for the evolution of sex chromosomes. Theor. Appl. Genet. 2004, $108,238-242$.

23. Peil, A.; Flachowasky, H.; Schumann, E.; Weber, W.E. Sex-linked AFLP markers indicate a pseudoautosomal region in hemp (Cannabis sativa L.). Theor. Appl. Genet. 2003, 107, 102-109.

24. Ainsworth, C.; Lu, J.; Winfield, M.; Parker, J.S. Sex Determination by X Autosome Dosage Rumex acetosa (sorrel). In Sex Determination in Plants; Ainsworth, C.C., Ed.; Bios Scientific Publishers: Oxford, UK, 1999; pp. 121-136.

25. Golan-Goldhirsh, A.; Jones, R.; Rowland, L.J. AFLP markers for sex determination in an ilex species. Acta Hort. 2001, 546, 591-595.

26. Golan-Goldhirsh, A.; Barazani, O.; Wang, Z.S.; Khadka, D.K.; Saunders, J.A.; Kostiukovsky, V.; Rowland, L.J. Genetic relationships among Mediterranean Pistacia species evaluated by RAPD and AFLP markers. Plant Syst. Evol. 2004, 246, 9-18.

27. Rogers, S.O.; Bendich, A.J. Extraction of DNA from plant tissue. In Plant Molecular Biology Manual; Kluwer Academic Publish: Dordrecht, The Netherlands, 1988; pp. 1-10.

28. Ainsworth, C. Boys and girls come out to play: The molecular biology of dioecious plants. Ann. Bot. 2000, 86, 211-221.

29. Sharma, S.K.; Knox, M.R.; Ellis, T.H.N. AFLP analysis of the diversity and phylogeny of Lens and its comparison with RAPD analysis. Theor. Appl. Genet. 1996, 93, 751-758.

30. Russell, J.R.; Fuller, J.D.; Macaulay, M.; Hatz, B.G.; Jahoor, A.; Powell, W.; Waugh, R. Direct comparison of levels of genetic variation among barley accessions detected by RFLPs, AFLPs, SSRs, and RAPDs. Theor. Appl. Genet. 1997, 95, 714-722.

31. Pejic, I.; Ajmone, M.P.; Morgante, M.; Kozumplick, V.; Castiglioni, P.; Taramino, G.; Motto, M. Comparative analysis of genetic similarity among maize inbred lines detected by RFLPs, RAPDs, SSRs, and AFLPs. Theor. Appl. Genet. 1998, 97, 1248-1255.

32. Khandka, D.K.; Tuna, M.; Tal, M.; Nejidat, A.; Golan-Goldhirsh, A. Variability in the pattern of random amplified polymorphic DNA. Electrophoresis 1997, 18, 2852-2856.

33. Lucchini, V. AFLP: A useful tool for biodiversity conservation and management. C.R. Biol. 2003, 326, S43-S48.

34. Hong, D.F.; Wan, L.L.; Liu, P.W.; Yang, G.S.; He, Q.B. AFLP and SCAR markers linked to the suppressor gene $(R f)$ of a dominant genetic male sterility in rapeseed (Brassica napus L.). Euphytica 2006, 151, 401-409.

35. Paran, I.; Michelmore, R.W. Development of reliable PCR-based markers linked to downy mildew resistance genes in lettuce. Theor. Appl. Genet. 1993, 85, 985-993.

(C) 2011 by the authors; licensee MDPI, Basel, Switzerland. This article is an open access article distributed under the terms and conditions of the Creative Commons Attribution license (http://creativecommons.org/licenses/by/3.0/). 